\title{
A Structural Analysis of Senior High School Students' English Achievement Goal Orientation, Learning Anxiety, and Autonomous Learning Behavior
}

\author{
CHEN Jun \\ Qiannan Normal University for Nationalities, Duyun, China \\ HUANG Zai-xiu \\ Hengda Branch of Zunyi Hangtian Middle School, Zunyi, China
}

\begin{abstract}
The present study aimed to investigate senior high school students to explore the relationships among their English achievement goal orientations, learning anxiety, and autonomous learning behavior. 748 first-year senior high school students in Guizhou Province, China were selected as participants. A comprehensive questionnaire measuring the above variables was designed to collect the data. The Structural Equation Modeling (SEM) was used to analyze the data. The results showed that the model had good fit to the sample. The students' mastery goals and performance-approach goals positively contributed to their autonomous learning behavior, whereas their performance-avoidance goals were negatively associated with their autonomous learning behavior. The students' mastery goals effectively reduced their learning anxiety, but their performance-approach goals and performance-avoidance goals engendered learning anxiety. The students' learning anxiety and their autonomous learning behavior were negatively correlated.
\end{abstract}

Keywords: achievement goal orientation, learning anxiety, autonomous learning behavior

\section{Introduction}

As the "student-centered" teaching idea was proposed in 1970s, learners have been the focus of researchers. Studies showed that learners' affective factors are key factors affecting their efficiency of foreign language learning. The affective factors include learners' anxiety, self-efficacy, motivation, etc. Motivation has been one of the researchers' focuses among these affective factors. The achievement goal orientation, as an important variable of motivation, has gained more attention with motivation research development in recent years. Motivation is an embodiment of learners' psychology related to learning and society, which is inevitably influenced by learners' socio-cultural background (Wei, 2014). The role of learning motivation related to achievement seems to be more obvious on the context of the college entrance examination in China. Therefore, the study on senior high school students' English achievement goal orientation is of great significance in English learning motivation research. The purpose of this study was to investigate senior high school students'

CHEN Jun, Ph.D., Professor, M.A. supervisor, School of Foreign Languages, Qiannan Normal University for Nationalities, Duyun, China.

HUANG Zai-xiu, teacher, Hengda Branch of Zunyi Hangtian Middle School, Zunyi, China. 
English learning achievement goal orientation in relation to their learning anxiety and autonomous learning behavior. This study may provide some valuable reference for guiding senior high school students to properly set their English learning goals so as to enhance their English learning.

\section{Literature Review}

\section{Achievement Goal Orientation}

Achievement goal orientation refers to the purpose of actions and behavior in achievement situations. It is a reflection of individual's cognition and emotion and behavior (Zimmerman, 1989). Achievement goal orientation was divided into mastery goals and the performance goals in the early stage (Dweck, 1986). Later, the performance goals were classified into performance-approach goals and performance-avoidance goals (Middleton \& Midgley, 1997). Based on the previous classifications, some researchers proposed a three-factor framework of achievement goal orientation, including mastery goals, performance-approach goals, and performance-avoidance goals. Individuals with mastery goals attach importance to improving themselves, and they make efforts to improve their skills and abilities (Dweck \& Elliot, 1983); individuals with performance-approach goals are more interested in proving their competence and gaining favorable judgments, and they care more about achievement, scores, and outperforming others; performance-avoidance goals take place when individuals are concerned about how to avoid being inferior or worse than others (Dweck \& Leggett, 1988). As the three-factor framework has been widely used in the previous studies (Bipp, Steinmayr, \& Spinath, 2008), the framework was applied in the present study to explore the relationships among the students' English achievement goal orientation, learning anxiety, and autonomous learning behavior in senior high schools.

\section{Foreign Language Anxiety}

Horwitz, Horwitz, and Cope (1986) first proposed foreign language anxiety. They believed that foreign language anxiety is a distinct complex of self-perceptions, beliefs, feelings, and behaviors related to classroom language learning arising from the uniqueness of the language learning process. In terms of the effect of foreign language anxiety on foreign language learning, the findings are various. Some studies found that moderate foreign language anxiety is helpful for learners to learn a foreign language (Chastain, 1975; Papi, 2010), while some studies found that foreign language anxiety may hinder foreign language learning (Guo \& Qin, 2010; Liu, Yao, \& Hu, 2012). Scovel (1978) pointed out that the former can be defined as facilitating anxiety; the latter can be defined as debilitating anxiety. Foreign language anxiety, as a key affective factor influencing foreign language learning, is bound to be affected by learner's achievement goal orientation of foreign language learning (Wei, 2014).

\section{Autonomous Learning Behavior}

The Senior High School English New Curriculum Standard (2017 Edition) in China identified four core accomplishments, which included language ability, cultural awareness, thinking quality, and learning ability (The Ministry of Education of the People's Republic of China, 2018). Autonomous learning, as a learning ability, not only influences individual's learning achievement but also is a pre-condition of lifelong learning. Students with autonomy can plan, organize, monitor, and evaluate their own learning throughout the learning process. This behavior is embodied as "creating an environment to support learning, and seeking help when it is necessary, and they are self-directed during learning and reinforcement process" (Karabenick \& Knapp, 1990). 
Therefore, learners with autonomy have the following behavioral features: setting clear goals, managing learning time, and correctly using metacognitive strategies, etc. (Zimmerman \& Paulsen, 1995).

\section{Research on the Relationships Among the Three Variables}

Researchers in China and abroad have conducted some studies on the relationships among learners' foreign language learning achievement goal orientation, learning anxiety, and autonomous learning behavior. Some studies found that college students' test anxiety was negatively related to their mastery goals, while positively related to performance-avoidance goals (Stana \& Opreab, 2015; Zhu, 2014). There was weak or zero correlation between performance-approach goals and learning anxiety (Elliot \& McGregor, 1999; Pekrun, Elliot, \& Maier, 2009). College students' autonomous learning behavior was positively related to their mastery goals and performance-approach goals (Zhou, Sang, \& Ge, 2010; Sun, 2015; Middleton \& Midgley, 1997), while there was no significant correlation between students' autonomous learning behavior and performance-avoidance goals ( $\mathrm{Li} \& \mathrm{Xu}, 2014$ ). Some studies found that college students' autonomous learning behavior was negatively related to their learning anxiety (Abdullah, 2016; Yin, Liu, \& Ye, 2018).

Through the literature review, it was found that some studies have investigated the relationships among students' achievement goal orientation, learning anxiety, and autonomous learning behavior in China and abroad. However, the studies combining three variables for research are still few. In China, few studies have taken senior high school students into consideration. Therefore, this study attempted to explore the relationships among the senior high school students' English achievement goal orientation, learning anxiety, and autonomous learning behavior on the context of the college entrance examination in Guizhou Province, China.

\section{Research Methodology}

\section{Research Hypothesis}

Based on the previous studies, the researcher made a conceptual model about the relationships among students' English achievement goal orientation, learning anxiety, and autonomous learning behavior, as shown in Figure 1.

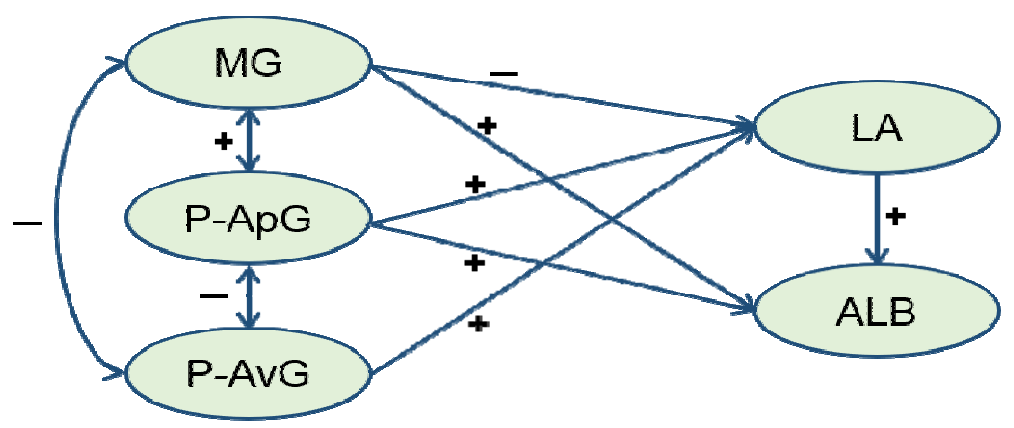

Figure 1. The conceptual model.

According to the conceptual model, the mastery goals (MG) was hypothesized to be positively related to the performance-approach goals (P-ApG) and negatively related to the performance-avoidance goals (P-AvG); the performance-approach goals $(\mathrm{P}-\mathrm{ApG})$ were negatively correlated with the performance-avoidance goals (P-AvG). The mastery goals (MG) were hypothesized to be positively related to the autonomous learning behavior (ALB) and negatively related to the learning anxiety (LA); the performance-approach goals (P-ApG) were positively correlated with the autonomous learning behavior (ALB) and the learning anxiety (LA); the 
performance-avoidance goals (P-AvG) were positively related to the learning anxiety (LA), while there was no correlation between the performance-avoidance goals $(\mathrm{P}-\mathrm{AvG})$ and the autonomous learning behavior (ALB). The learning anxiety (LA) was hypothesized to negatively relate to the autonomous learning behavior (ALB).

\section{Participants for the Present Study}

In the present study, 748 first-year students from four senior high schools in Guizhou Province, China were chosen through simple random sampling as the participants. Among them, 277 were males and 471 were females. 40 students were selected for the semi-structured interviews.

\section{Development of Research Instruments}

In the present study, a comprehensive questionnaire consisting of three sub-questionnaires measuring the students' English achievement goal orientation, learning anxiety, and autonomous learning behavior respectively was designed to collect the data. The questionnaire adopted a four-point rating scale $(1=$ never true of me; 2 = usually not true of me; 3 = usually true of me; 4 = always true of me). The exploratory factor analysis was used to test the construct validity of each sub-questionnaire. The Cronbach's Alpha was used to measure the reliability of each sub-questionnaire. In addition, a semi-structured interview was conducted to get in-depth information about students' ideas concerning their English achievement goal orientation, learning anxiety, and autonomous learning behavior.

English achievement goal orientation questionnaire. The English achievement goal orientation questionnaire was adapted from Wei's (2014) questionnaire, which was designed based on the previous studies (Elliot, 1999; Midgley, Kaplan, Middleton, \& Maehr, 1998). The researcher did some modifications about the items based on the feedbacks from the students in interviews and the advice from some English teachers in senior high schools. The final questionnaire included 19 items. The KMO value of the questionnaire was 0.923 and the Bartlett's Sphericity Test was significant $(p<0.001)$, which indicated that the data met the requirements of factor analysis. Three factors, which were respectively named as the performance-approach goal, the mastery goal, and the performance-avoidance goal, were extracted through the principal component analysis with varimax rotation. A total of $65.10 \%$ variance of the questionnaire was explained by the three factors. The results showed that the questionnaire had good construct validity. The Cronbach's Alpha of the questionnaire was 0.877 , which was higher than the acceptable value 0.070 .

English learning anxiety questionnaire. The English learning anxiety questionnaire was based on the Foreign Language Classroom Anxiety Scale (FLCAS) of Horwitz et al. (1986). 18 items were selected from the original questionnaire with some modifications and six items were added according to the interviews with 20 senior high school students. The final questionnaire contained 24 items. The KMO of the questionnaire was 0.944 ( $>0.5)$, and the $\mathrm{p}$ value of the Bartlett's Sphericity Test was smaller than 0.001 , which indicated the data met the requirements of factor analysis. Through the principal component factor analysis and varimax rotation, four factors were extracted based on the scree plot and rotated component matrix. The four factors were respectively named as nervousness, worry, fear of questions in class, and communication apprehension. The four factors could totally explain $63.75 \%$ variance of the questionnaire. The results showed the questionnaire had good construct validity. The Cronbach's Alpha of the questionnaire was 0.926 .

Autonomous English learning behavior questionnaire. The autonomous English learning behavior questionnaire was adapted from the previous studies of Pintrich, Smith, Garcia, and McKeachie (1991), Lin (2013), and Wei (2014). The researcher adapted four items from Pintrich's (1991), six items from Lin's (2013), 
and three items from Wei's (2014). One item was added based on the interviews. The items selected from the above researchers were modified based on the feedbacks from the students in the interviews. The KMO of the questionnaire was 0.949 and Bartlett's Sphericity test was significant $(p<0.001)$, which indicated the data were suitable for conducting a factor analysis. The principal component analysis was adopted for factor extraction. The scree plot and rotated component matrix showed that two factors could be extracted, which were respectively named as metacognitive strategies and resource management strategies. The two factors could totally explain $65.49 \%$ variance of the questionnaire. These results indicated the scale had good construct validity. The Cronbach's Alpha of the questionnaire was 0.923 .

Semi-structured interview. Interview enjoys popularity among qualitative research because it can be used to obtain in-depth information concerning participants' thoughts, beliefs, knowledge, reasoning, motivations, and feelings about intended topics (Johnson \& Christensen, 2012). In the present study, semi-structured interviews were conducted after the participants responded to the questionnaires in order to deeply understand the students' ideas while filling the questionnaires. The semi-structured interview included five open-ended questions.

\section{Data Analysis}

The SPSS program was used to process the data obtained from the questionnaires, and then the AMOS program was used to conduct the Structural Equation Modeling (SEM) analysis. The SEM analysis is a measure to evaluate the fit degree between the hypothesis model and the sample data to determine whether the hypothetical model proposed by the researcher can be applied to the sample data $(\mathrm{Wu}, 2010)$. The better the fit is, the closer the model is to the sample. In the present study, several fit indices were used to evaluate the fit degree of the model. These fit indices included CMIN/DF, GFI, AGFI, RMSEA, IFI, CFI, and TLI (NNFI). When most fit indices met the SEM standards, the model could be considered to have good fit to the data. Finally, the standardized path coefficients in the model were presented to show the relationships among students' English achievement goal orientation, learning anxiety, and autonomous learning behavior.

\section{Results}

The followings are the findings of the present study. Several fit indices were selected to evaluate the fit degree of the model. The acceptable range of the fit indices and the measurements of the present study were presented. Then, the model and standardized path coefficients were presented to show the relationships among students' English achievement goal orientation, learning anxiety, and autonomous learning behavior.

Table 1

Model Fit Indices

\begin{tabular}{lll}
\hline Fit index & Acceptable range & Measurements \\
\hline CMIN/DF & $<3$ & 1.492 \\
RMSEA & $<0.05$ & 0.026 \\
GFI & $>0.9$ & 0.903 \\
AGFI & $>0.9$ & 0.895 \\
IFI & $>0.9$ & 0.969 \\
TLI(NNFI) & $>0.9$ & 0.967 \\
CFI & $>0.9$ & 0.969 \\
\hline
\end{tabular}


As shown in Table 1, the CMIN/DF was 1.429, smaller than 3. The values of the GFI, the IFI, the TLI, and the CFI were $0.903,0.969,0.967$, and 0.969 , which were greater than the acceptable value 0.9. The AGFI was 0.895 , which was a little lower than 0.9 ; however it was acceptable according to some previous studies, such as Baumgartner and Homburg (1996) and Doll, Xia, and Torkzadeh (1994). The RMSEA was 0.026, which was smaller than the acceptable range 0.05 . These results revealed that the fit indices met the SEM standards, which indicated that this model had good fit. The following presented the model and standardized path coefficients.

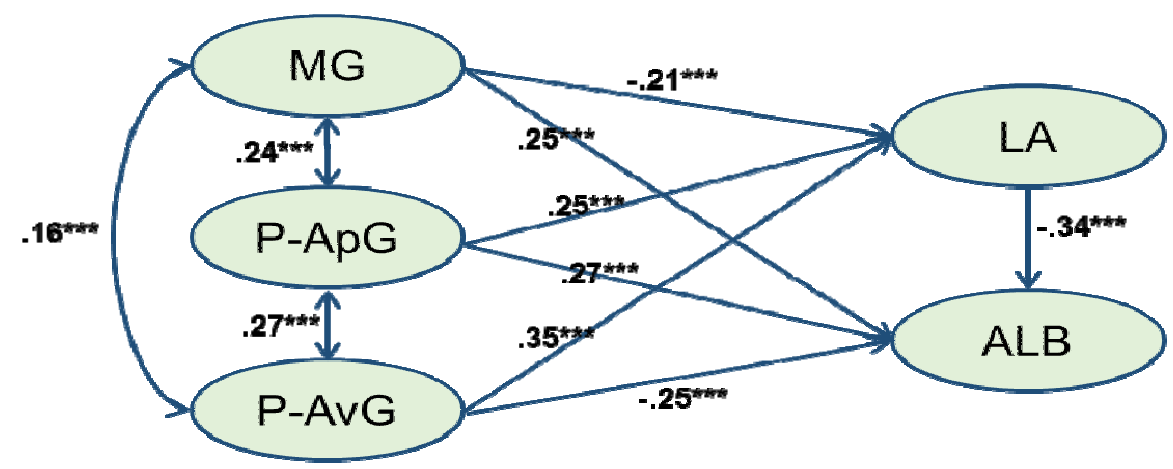

Figure 2. The model and standardized path coefficients.

As presented in Figure 2, all the structural paths in the model were significant. Compared with the conceptual model, most of the hypothesized correlations among the variables were verified, but three hypotheses were rejected. The students' achievement goals had different relationships with their learning anxiety and autonomous learning behavior. The covariance between the three achievement goals were all positive and significant ( $\varnothing=0.24$ between the MG and the P-ApG, $\varnothing=0.27$ between the P-ApG and the P-AvG, and $\varnothing=0.16$ between the MG and the P-AvG).

As shown in the figure, the students' MG were positively related to their ALB ( $\beta=0.25, p<0.001)$, but negatively correlated with their LA $(B=-0.21, p<0.001)$. It means that the students' mastery goals could enhance their autonomous learning behavior; the students with higher mastery goal orientation had lower learning anxiety. The students' P-ApG positively contributed to their ALB $(\beta=0.27, \mathrm{p}<0.001)$ and LA ( $(=$ $0.25, p<0.001)$, indicating that the students' performance-approach goals may increase their autonomous learning awareness, but in the meantime it would also increase their learning anxiety. The students' P-AvG positively related to their LA ( $(=0.35, \mathrm{p}<0.001)$, but negatively correlated with their autonomous learning behavior $(\beta=-0.25, p<0.001)$, which indicates the students' performance-avoidance goal orientation could increase their learning anxiety and hinder their autonomous learning behavior. The students' learning anxiety negatively correlated to their autonomous learning behavior $(B=-0.34, p<0.001)$, which means the students' learning anxiety had negative influence on their autonomous learning behavior.

\section{Discussion}

\section{Relationships Between Achievement Goal Orientations and Learning Anxiety}

The findings of the present study revealed that the students' mastery goals were negatively related to their English learning anxiety, while their performance-approach goals and performance-avoidance goals were positively related to English learning anxiety. The findings were coincided with Stana and Opreab (2015) and 
Zhang and Yuan (2004). Zhang and Yuan (2004) pointed out that students' mastery goals could lower their English learning anxiety; their performance-approach goal may lead to higher English learning anxiety. Hao and Hao (2001) made an explanation for that: People who pursue high achievement motivation are eager for success, and they like to challenge difficult tasks, while those who have high motivation of avoiding failure are likely to be worried, uneasy, and afraid, etc.

In the present study, the mean scores of students' English achievement goals from the highest to the lowest were in sequence of the mastery goal, the performance-approach goal, and the performance-avoidance goal. The students with higher mastery goal tended to challenge themselves, paid attention to the development of their English knowledge and skills, and had confidence in English learning. Therefore, their English learning anxiety was lower. At the same time, foreign language education in Guizhou Province is relatively backward and the pursuit to high scores is the main goal of many students. Hence, the students with higher performance-approach goal are more likely to have higher English learning anxiety.

The students' performance-approach goals and performance-avoidance goals were positively related to their English learning anxiety, but the impact of the students' performance-avoidance goals on their English learning anxiety was greater than that of their performance-approach goals. The finding was consistent with the study by Elliot and Harackiewicz (1996). This phenomenon could be explained by the results of the interviews with the students. Compared with the students with higher performance-approach goals, the students with higher performance-avoidance goals were more worried about the negative comments from classroom questions and exams. Therefore, they were prone to be anxious.

\section{Relationships Between Achievement Goal Orientations and Autonomous Learning Behavior}

In the present study, the students' mastery goals and performance-approach goals were positively related to their autonomous English learning behavior. The findings were in accordance with Middleton and Midgley (1997) and Zhou, Sang, and Ge (2010). In the interviews, it was found that the students with high mastery goals had clear learning aims, and tended to actively adopted various autonomous learning strategies to improve their English knowledge and skills. The students with high performance-approach goals paid more attention to their English scores. They tried to employ various learning strategies to improve their scores in order to obtain favorable comments from their teachers and classmates. The students' performance-avoidance goal and their autonomous English learning behavior were negatively correlated, which showed that the higher the students' performance-avoidance goals were, the lower their autonomous English learning behavior was. Based on the interviews, it was found that the students with higher performance-avoidance goals usually had lower English learning motivation; they were inclined to avoid their deficiency of English learning; they were more passive in the learning process and had lower autonomy in English learning.

The students' mastery goals and performance-approach goals were positively related to their autonomous English learning behavior, but the impact of the performance-approach goals on autonomous English learning behavior was greater than that of the mastery goals. This finding confirmed the view of Barron and Harackiewicz $(2001 ; 2003)$ that the positive effect of the performance-approach goals was more significant on the education context dominated by competition. The students with higher performance-approach goals were more concerned about their grades, scores, and favorable comments from others, so they took the initiative to adopt some autonomous English learning strategies to improve their English proficiency. 


\section{Relationships Between Learning Anxiety and Autonomous Learning Behavior}

The study revealed that there were negative relationships between the students' English learning anxiety and their autonomous learning behavior, which confirmed the view that learners' English learning anxiety may hinder their English learning (Yin, Liu, \& Ye, 2018; Abdullah, 2016). The results in the present study could be explained by the relationships between the students' mastery goals, learning anxiety, and autonomous English learning behavior as stated above. The students with higher mastery goal had lower learning anxiety and had higher autonomous English learning awareness. Then it is not difficult to understand why the students' learning anxiety negatively contributed to their autonomous learning. Through the interview, it was found that the students with high anxiety were usually very passive and stressed in English language learning, and they even felt difficult to finish the daily tasks given by their teachers. Thus, there was no much time for them to manage their own learning behaviors.

\section{Conclusion}

Using questionnaires and semi-structured interviews to collect the data, this study investigated the correlations among the senior high school students' English achievement goal orientation, learning anxiety, and autonomous learning behavior. The analysis of the Structural Equation Modeling (SEM) showed that the model had good fit to the data. The students' mastery goal orientation negatively correlated with their English learning anxiety and positively contributed to their autonomous learning behavior, which indicates that the students' mastery goal orientation may deduce their English learning anxiety and increase their autonomous learning awareness. The students' performance-approach goal orientation positively related to their learning anxiety and autonomous learning. It means that the students' performance-approach goal orientation may engender their learning anxiety, but it can effectively promote the students' learning behavior. The students' performance-avoidance goal orientation had positive relationship with their learning anxiety and negative relationship with their autonomous learning behavior, indicating the students' performance-avoidance goal orientation may increase their learning anxiety and decrease their autonomous learning behavior. The negative correlation between the students' English learning anxiety and their autonomous learning behavior indicates students' learning anxiety may hinder their autonomous learning behavior.

According to the findings, the EFL teachers in senior high schools should take the followings into consideration: (1) to guide the students to regard the mastery of English knowledge and skills as their major goals to establish positive English learning attitude; (2) to create harmonious classroom atmosphere to reduce the students' English learning pressure and anxiety, and enhance their awareness of autonomous learning; (3) to conduct frustration education to change students' negative attitude towards failure to reduce the negative impact of the avoidance goals; (4) to train the students to effectively employ autonomous English learning strategies to promote their autonomous learning awareness and behaviors. These measures may help students to establish positive English achievement goal orientation, effectively lower English learning anxiety, and engage in English learning with positive attitude to improve their English proficiency.

\section{References}

Abdullah, M. N. L. Y. (2016). Interaction effects of gender and motivational beliefs on self-regulated learning: A study at ICT-integrated schools. Malaysian Journal of Learning and Instruction, 13, 25-41.

Baron, K. E., \& Haradkiewicz, J. M. (2001). Achievement goals and optimal motivation: Testing multiple goal models. Journal of Personality and Social Psychology, 80(5), 706. 
Baron, K. E., \& Harackiewicz, J. M. (2003). Revisiting the benefits of performance-approach goals in the college classroom: Exploring the role of goals in advanced college courses. International Journal of Educational Research, 39(4), 357-374.

Baumgartner, H., \& Homburg, C. (1996). Applications of structural equation modeling in marketing and consumer research. International Journal of Research in Marketing, 13, 139-161.

Bipp, T., Steinmayr, R., \& Spinath, B. (2008). Personality and achievement motivation: Relationship among big five domain and facet scales, achievement goals, and intelligence. Personality and Individual Differences, 44(7), 1454-1464.

Chastain, K. (1975). Affective and ability factors in second language learning. Language Learning, 25, 153-161.

Doll, W. J., Xia, W., \& Torkzadeh, G. (1994). A confirmatory factor analysis of the end-user computing satisfaction instrument. MIS Quarterly, 18(4), 453-461.

Dweck, C. S., \& Leggett, E. L. (1988). A social cognitive approach to motivation and personality. Psychological Review, 95(2), 256-273.

Dweck, C. S., \& Elliott, E. S. (1983). Achievement motivation. Socialization, personality, and social development. New York: Wiley.

Dweck, C. S. (1986). Motivational processes affecting learning. American Psychologist, 41(10), 1040-1048.

Elliot, A. J., \& Harackiewicz, J. M. (1996). Approach and avoidance achievement goals and intrinsic motivation: A meditational analysis. Journal of Personality and Social Psychology, 70(3), 461-475.

Elliot, A. J., \& McGregor, H. A. (1999). Test anxiety and the hierarchical model of approach and avoidance achievement motivation. Journal of Personality and Social Psychology, 76(4), 628-644.

Elliot, A. J. (1999). Approach and avoidance motivation and achievement goals. Educ. Psychol., 34(3), 169-189.

Guo, Y., \& Qin, X. Q. (2010). The foreign language writing anxiety test report of Chinese non-English majors and its implications for writing teaching. Foreign Language World, (2), 54-62.

Hao, M., \& Hao, R. P. (2001). A study on the relationships between English achievement, achievement motivation and state anxiety. Foreign Language Teaching and Research, (2), 111-115.

Horwitz, E. K., Horwitz, M. B., \& Cope, J. (1986). Foreign language classroom anxiety. The Modern Language Journal, 70, 125-132.

Johnson, B., \& Christensen, L. (2012). Educational research: Quantitative, qualitative, and mixed approaches. Thousand Oaks, California: Sage Publications.

Karabenick, S. A., \& Knapp, J. R. (1990). Relationship of academic help seeking to the use of learning strategies and other instrumental achievement behavior in college students. Journal of Educational Psychology, 83(2), 221-230.

Li, B. B., \& Xu, J. F. (2014). The influence of achievement goal orientation on autonomous English learning ability and the intermediary role of self-efficacy. Foreign Languages in China, 11(3), 59-68.

Lin, L. L. (2013). Compilation and test of college students' autonomous English learning ability scale based on three dimensional concepts. Foreign Language World, (4), 73-96.

Liu, Z., Yao, X. J., \& Hu, S. F. (2012). A structural analysis of college students' L2MSS, anxiety and motivation learning behavior. Foreign Language World, (6), 28-37.

Middleton, M. J., \& Midgley, C. (1997). Avoiding the demonstration of lack of ability: An underexplored aspect of goal theory. Journal of Educational Psychology, (89), 710-718.

Midgley, C., Kaplan, A., Middleton, M., \& Maehr, M. L. (1998). The development and validation of scales assessing students' achievement goal orientations. Contemporary Educational Psychology, (23), 113-131.

Papi, M. (2010). The L2 motivational self-system, L2 anxiety, and motivated learning behavior: A structural equation modeling approach. System, (38), 467-479.

Pekrun, R., Elliot, A. J., \& Maier, M. A. (2009). Achievement goals and achievement emotions: Testing a model of their joint relations with academic performance. Journal of Educational Psychology, 101(1), 115-135.

Pintrich, P. R., Smith, D. A. F., Garcia, T., \& McKeachie, W. J. (1991). A manual for the use of the Motivated Strategies for Learning Questionnaire (MSLQ). Ann Arbor, MI: The University of Michigan Press.

Rong, T. S. (2009). AMOS and research methods. Chongqing: Chongqing University Press.

Scovel, T. (1978). The effect of affect on foreign language learning: A review of the anxiety literature. Language Learning, (28), 129-142.

Stan, A., \& Oprea, C. (2015). Test anxiety and achievement goal orientations of students at a Romanian university. Procedia-Social and Behavioral Sciences, 180, 1673-1679. 
Sun, E. P. (2015). A study on the relationship between achievement goal orientation and autonomous learning behavior. Zhaotong University Journal, 37(6), 94-97.

The Ministry of Education of the People's Republic of China. (2018). The senior high school English new curriculum standard (2017 edition). Beijing: People's Education Press.

Wei, X. B. (2014). A structural analysis of college students' English achievement goal orientation, learning anxiety and autonomous learning behavior. Foreign Language World, (4), 12-38.

Wu, M. L. (2010). Structural equation modeling: AMOS operation and application. Chongqing: Chongqing University Press.

Yin, S. Y., Liu, Q. L., \& Ye, X. B. (2018). An empirical study of students' anxiety and autonomous English learning ability in Xinjiang. Journal of Zunyi Normal University, 20(5), 153-158.

Zhang, W. J., \& Yuan, L. X. (2004). The influence of achievement goal orientation on foreign language learning of non-English major college students. Media Foreign Language Instruction, (5), 21-25.

Zhou, Y. G., Sang, Q. S., \& Ge, M. G. (2010). A study on the relationships among college students' autonomous learning, achievement goal orientation and academic achievement. Psychological Science, (1), 194-197.

Zhu, X. Y. (2014). A study on the relationships among college students' achievement goal orientation, English learning anxiety and English achievement. Wuyi University Journal, 16(2), 90-95.

Zimmerman, B. J., \& Paulsen, A. S. (1995). Self-monitoring during collegiate studying: An invaluable tool for academic self-regulation. In P. R. Pintrich (Ed.), Understanding self-regulated learning (pp. 13-27). San Francisco: Jossey Bass.

Zimmerman, B. J. (1989). A social cognitive view of self-regulated academic learning. Journal of Educational Psychology, 81(3), 329-339. 


\section{Appendix \\ English Learning Questionnaire of Senior High School Students}

Dear students,

This questionnaire was designed to understand the English learning situation of senior high school students. I hope that you can answer the questions according to your situation. The answer is no good or bad, right or wrong, the questionnaire is not registered, and the results obtained are just for research analysis. Thanks for your cooperation.

\section{Part 1: Personal Information}

Instruction: Please according to personal situation, put a tick " $\sqrt{ }$ " in each box " $\square$ " of the choices given or write down some information where necessary.

1. School:

2. Gender: $\square$ Male $\square$ Female

3. Minority: $\square$ Han Minority $\square$ Minority Nationalities

4. Discipline: $\square$ Arts $\square$ Science

5. Your English achievement in Senior High School Entrance is:

6. Do you like English? $\square$ Like $\square$ Dislike

\section{Part 2: English Learning Situation}

Please draw " $\sqrt{ }$ " in the option that best suits your situation. There is no right or wrong answer. There are only personal opinions. Please do not choose many or none. Please check items depending on your situation.

Notes: 1 = never true of me; 2 = usually not true of me; 3 = usually true of me; 4 = always true of me

\begin{tabular}{|c|c|c|c|c|}
\hline English learning situation & 1 & 2 & 3 & 4 \\
\hline 1. I learn English for interest. & 1 & 2 & 3 & 4 \\
\hline 2. I like English because it helps me learn more new knowledge. & 1 & 2 & 3 & 4 \\
\hline 3. I spend much time learning English after class in order to improve my English. & 1 & 2 & 3 & 4 \\
\hline 4. I like the challenging tasks in English classes so that I can make great progress. & 1 & 2 & 3 & 4 \\
\hline 5. I like the content that stimulates my interest in English class, even if it is difficult to master. & 1 & 2 & 3 & 4 \\
\hline 6. One of the goals of my English class is to learn as much English as possible. & 1 & 2 & 3 & 4 \\
\hline 7. I also learn the content beyond the English exam. & 1 & 2 & 3 & 4 \\
\hline 8. I learn English for good score in college entrance examination. & 1 & 2 & 3 & 4 \\
\hline 9. I feel good about myself when I can answer the questions of the English teacher. & 1 & 2 & 3 & 4 \\
\hline 10. I want to perform better than others in English class. & 1 & 2 & 3 & 4 \\
\hline $\begin{array}{l}\text { 11. In English learning, I will have a great sense of achievement if I perform better than other classmates in } \\
\text { class. }\end{array}$ & 1 & 2 & 3 & 4 \\
\hline 12. I want to prove to my teachers and classmates that I am very talented in English learning. & 1 & 2 & 3 & 4 \\
\hline 13. I really care about doing better in English learning than other classmates. & 1 & 2 & 3 & 4 \\
\hline 14. The goal of my English learning is to surpass most of the classmates in the class. & 1 & 2 & 3 & 4 \\
\hline 15. I make efforts to get good score to prove my ability in the English exam. & 1 & 2 & 3 & 4 \\
\hline 16. The reason why I do my homework is that I don't want to be embarrassed in front of my classmates. & 1 & 2 & 3 & 4 \\
\hline 17. I learn English for fear of failing the exam. & 1 & 2 & 3 & 4 \\
\hline 18. One of my goals in learning English is to avoid other classmates think I am stupid in learning English. & 1 & 2 & 3 & 4 \\
\hline 19. I have low participation in the English class in order to avoid mistakes in front of my classmates. & 1 & 2 & 3 & 4 \\
\hline 20. I am worried that the failure of the English exam will be criticized by the teacher and family. & 1 & 2 & 3 & 4 \\
\hline 21. The progress of English classes is fast, and I am afraid I can't catch up with it. & 1 & 2 & 3 & 4 \\
\hline 22. I am very upset when I don't understand what the English teacher is saying. & 1 & 2 & 3 & 4 \\
\hline
\end{tabular}




\begin{tabular}{|c|c|c|c|c|}
\hline English learning situation & 1 & 2 & 3 & 4 \\
\hline 23. Some quizzes in the English class make me nervous. & 1 & 2 & 3 & 4 \\
\hline 24. I am worried that my English is behind other classmates. & 1 & 2 & 3 & 4 \\
\hline 25. Although I prepare for English class well, I still feel anxious. & 1 & 2 & 3 & 4 \\
\hline 26. I am worried that I fail to pass the English exam. & 1 & 2 & 3 & 4 \\
\hline 27. I have no confidence in speaking in English class. & 1 & 2 & 3 & 4 \\
\hline 28. Learning so many grammar rules makes me afraid. & 1 & 2 & 3 & 4 \\
\hline 29. I am nervous when I am in English class. & 1 & 2 & 3 & 4 \\
\hline 30. The more I prepare for English exam, the more nervous I am. & 1 & 2 & 3 & 4 \\
\hline 31. The English teacher is strict and I am very nervous in class. & 1 & 2 & 3 & 4 \\
\hline 32. I am nervous when I see new words in exam. & 1 & 2 & 3 & 4 \\
\hline 33. I am worried that I have no enough time for English exam. & 1 & 2 & 3 & 4 \\
\hline 34. I feel stressed to prepare for English class. & 1 & 2 & 3 & 4 \\
\hline 35. I have no confidence in speaking English in front of other classmates. & 1 & 2 & 3 & 4 \\
\hline 36. Speaking English with unfamiliar people makes me nervous. & 1 & 2 & 3 & 4 \\
\hline 37. I have no confidence in speaking English in English class. & 1 & 2 & 3 & 4 \\
\hline 38. When I am speaking English, I am worried that other classmates laugh at me. & 1 & 2 & 3 & 4 \\
\hline 39. When the English teacher asks me questions, I feel nervous. & 1 & 2 & 3 & 4 \\
\hline 40. In the English class, I am nervous when I answer questions by myself. & 1 & 2 & 3 & 4 \\
\hline 41. When the English teacher calls my name, my heart beats very fast. & 1 & 2 & 3 & 4 \\
\hline 42. I am scared when I speak without preparation in English class. & 1 & 2 & 3 & 4 \\
\hline 43. When I am asked to answer questions, I am so nervous that I forget everything I know. & 1 & 2 & 3 & 4 \\
\hline 44. I adjust my learning style based on the learning content and the teacher's teaching style. & 1 & 2 & 3 & 4 \\
\hline 45. I set phased goals to guide my English learning. & 1 & 2 & 3 & 4 \\
\hline 46. I evaluate my English learning and find out the problems and solutions. & 1 & 2 & 3 & 4 \\
\hline 47. I strengthen learning based on my weak points. & 1 & 2 & 3 & 4 \\
\hline 48. I ask myself if I understand what the teacher said. & 1 & 2 & 3 & 4 \\
\hline 49. I try to overcome boredom and stick to learn English. & 1 & 2 & 3 & 4 \\
\hline 50. After learning one or two units, I will test my learning outcome. & 1 & 2 & 3 & 4 \\
\hline 51. I will reflect and summarize my English learning methods. & 1 & 2 & 3 & 4 \\
\hline 52. I will find suitable learning materials based on my learning interests and needs. & 1 & 2 & 3 & 4 \\
\hline 53. I will summarize the wrong questions in the exam and use them as review materials for the next exam. & 1 & 2 & 3 & 4 \\
\hline 54. I will ask the teachers and classmates for help if I have trouble in learning English. & 1 & 2 & 3 & 4 \\
\hline 55. No matter how busy I am after class, I will squeeze time to learn English. & 1 & 2 & 3 & 4 \\
\hline 56. Before the exam, I will spend time reviewing my notes. & 1 & 2 & 3 & 4 \\
\hline 57. I will use dictionary, network and so on to assist my English learning. & 1 & 2 & 3 & 4 \\
\hline
\end{tabular}

